Akira Kudoh MD, *

Hironori Ishihara MD,

Akitomo Matsuki MD

\title{
Response to surgical stress in elderly patients and Alzheimer's disease
}

Purpose: To determine the effect of surgical stress on plasma epinephrine, norepinephrine, ACTH and cortisol concentrations in patients aged 80-99 yr and in patients complicated with Alzheimer's disease.

Methods: A prospective controlled study was undertaken in 55 undergoing surgical reduction of femur neck fracture in Hirosaki University hospital and Hakodate Watanabe hospital; 18 patients in 80-99 yr (Group I) and 18 patients in 40-59 yr (Group 2) and 7 patients (Group A) with and 12 patients (Group B) without Alzheimer's dementia $(A D)$ aged $60-79$ yr.

Results: The increase in plasma norepinephrine level (274\%) of group I patients, 15 min after skin incision was higher than that in group $2(191 \%)(P<0.01)$. Mean plasma cortisol levels $\left(40.4 \pm 4.7\right.$ and $\left.44.1 \pm 5.2 \mu \mathrm{g} \cdot \mathrm{dl}^{-1}\right)$ of group I, 15 min after skin incision and $60 \mathrm{~min}$ after the end of surgery were significantly higher than the 29.8 \pm 3.5 and $22.3 \pm 3.0 \mu \mathrm{g} \cdot \mathrm{dl}^{-1}$ of group $2(P<0.05)$. Plasma norepinephrine $\left(1092.9 \pm 112.0 \mathrm{pg} \cdot \mathrm{ml}^{-1}\right)$ and cortisol concentrations $\left(53.4 \pm 5.8 \mu \mathrm{g} \cdot \mathrm{dl}^{-1}\right)$ in group $A$ were higher than in group $B\left(772.6 \pm 82.4 \mathrm{pg}^{\cdot} \mathrm{ml}^{-1}\right.$ and 41.7 $\left.\pm 4.3 \mu \mathrm{g} \cdot \mathrm{dl}^{-1}\right) 15 \mathrm{~min}$ after skin incision $(P<0.05)$.

Conclusions: Plasma norepinephrine and cortisol responses to surgical stress are activated in elderly patients and in patients with Alzheimer's disease.

Objectif : Déterminer l'effet du stress chirurgical sur la concentration plasmatique d'épinéphrine, de norépinéphrine, d'ACTH et de cortisol chez des patients de 80-99 ans et chez des patients atteints de la maladie d'Alzheimer.

Méthode : On a entrepris l'étude prospective et contrôlée de 55 patients, devant subir une réduction de fracture du col du fémur aux hôpitaux Hirosaki University et Hakodate Watanabe, répartis comme suit : 18 dans le Groupe I ( $80-99$ ans) et 18 dans le Groupe 2 (40-59 ans) ; 7 dans le Groupe A (démence d'Alzheimer DA) et 12 dans le Groupe $B$ (sans DA) âgés de 60-79 ans.

Résultats : L'augmentation de la norépinéphrine plasmatique (274\%) était plus grande chez les patients du Groupe I que chez ceux du Groupe $2(191 \%)$, 15 min après l'incision cutanée $(P<0,01)$. Les niveaux moyens de cortisol $\left(40,4 \pm 4,7\right.$ et $\left.44,1 \pm 5,2 \mu \mathrm{g} \cdot \mathrm{dl}^{-1}\right)$ du Groupe $1,15 \mathrm{~min}$ après l'incision cutanée et $60 \mathrm{~min}$ après la fin de la chirurgie, ont été plus élevés que les niveaux enregistrés dans le Groupe $2(29,8 \pm 3,5$ et 22,3 $\pm 3,0$ $\left.\mu \mathrm{g} \cdot \mathrm{dl}^{-1}\right)$ de façon significative $(P<0,05)$. Les concentrations plasmatiques de norépinéphrine $(1092,9 \pm 112,0$ $\mathrm{pg} \cdot \mathrm{ml}^{-1}$ ) et de cortisol $\left(53,4 \pm 5,8 \mu \mathrm{g} \cdot \mathrm{dl}^{-1}\right)$ étaient plus élevées dans le Groupe A que dans le Groupe $B(772,6$ $\pm 82,4 \mathrm{pg} \cdot \mathrm{ml}^{-1}$ et $\left.41,7 \pm 4,3 \mu \mathrm{g} \cdot \mathrm{dl}^{-1}\right) 15$ min après l'incision cutanée $(P<0,05)$.

Conclusion : Les changements plasmatiques de norépinéphrine et de cortisol reliés au stress chirurgical sont plus marqués chez les patients âgés ou souffrant de la maladie d'Alzheimer.

From the Division of Anesthesia, Hakodate Watanabe Hospital, ${ }^{*}$ Hakodate, 042-0932, Japan and the Department of Anesthesiology, University of Hirosaki School of Medicine, Hirosaki, 036, Japan.

Address correspondence to: Akira Kudoh MD, Department of Anesthesiology, University of Hirosaki School of Medicine, Honcho 53 , Hirosaki 036-8216, Aomori, Japan. Phone: 81-172-33-5111; Fax: 81-172-39-5112.

Accepted for publication November 30, 1998 
$\mathrm{R}$ EDUCED homeostatic capacity is a typical characteristic of the aging process and is most pronounced in changes in the neuroendocrine control to maintain cardiovascular homeostasis. As elderly patients have not only decreased B-adrenoceptor responsiveness, but also decreased baroreflex function and parasympathetic control of heart rate, they are often sensitive to vasodilators and anesthetics, leading to severe hypotension. Plasma concentrations of norepinephrine (NE) are higher in the elderly. ${ }^{1}$ The increase in NE with age may be caused by a compensatory mechanism for neuroendocrine change. ${ }^{2}$ The NE response to a variety of stress is also enhanced in elderly patients. ${ }^{3,4}$ On the other hand, the central noradrenergic system (CNS) is markedly vulnerable to the aging process. A decline in hypothalamic and hippocampal catecholamine activity has a critical role in the development of aging. ${ }^{5}$ Noradrenergic activity in Alzheimer's dementia (AD) is potentially important in the pathogenesis of this disorder and plasma NE concentrations may be an indication of the severity of $\mathrm{AD} .^{6}$ Thus, NE plays an important role in cardiovascular and CNS homeostasis in the elderly.

Alteration in hypothalamic-pituitary-adrenal (HPA) axis function frequently accompanies aging and results in increased plasma cortisol concentrations and increased adrenocortical responses to ACTH and stress. ${ }^{7,8}$ The change in the HPA axis would be associated with age-related hippocampal dysfunction, since the hippocampus plays an important role in HPA system. ${ }^{9}$ On the contrary, Brett et al. reported that elderly patients have a diminished adrenocortical response to acute and chronic stress. ${ }^{10}$ Patients with $\mathrm{AD}$ also develop disturbed regulation of HPA due to hippocampal degeneration..$^{11,12}$ Thus, the endocrine response to surgical stress in the elderly patient or in patients with $\mathrm{AD}$ may differ from that in younger adults. This study was designed to investigate the effects of surgical stress on plasma epinephrine (EPI), NE, ACTH and cortisol concentrations during general anesthesia in patients aged 80-99 and to determine whether $\mathrm{AD}$ influences stress hormone concentrations during surgery.

\section{Patients and methods}

The study was performed in Hirosaki University Hospital and Hakodate Watanabe hospital. The protocol was approved by institutional ethical committee of each hospital and informed consent was obtained from each patient.

Effect of aging on endocrine response to surgical stress Eighteen patients aged 80-99 yr (Group 1) and 18 aged 40-59 yr (Group 2) were randomly chosen before the study. All patients were undergoing surgical reduction of femoral neck fracture.

Effect of Alzheimer disease on response to surgical stress Seven patients (Group A) with and 12 (Group B) without Alzheimer's dementia (AD) aged 60-79 yr were randomly chosen before the study. The patients were undergoing surgical reduction of femoral neck fracture. The diagnosis of $\mathrm{AD}$ was made by psychiatrists according to DSM-IV.

All patients with a history of anemia $(\mathrm{Hb}<10$ $\left.\mathrm{g} \cdot \mathrm{dl}^{-1}\right)$, marked cardiovascular or respiratory disease and endocrine disorders were excluded and patients with vasopressor as ephedrine were excluded in this study. Patients with dehydration preoperatively were corrected by lactated Ringer's solution. Anesthesia was induced with $5 \mathrm{mg} \cdot \mathrm{kg}^{-1}$ thiopental iv and tracheal intubation was facilitated by $0.5-1.0 \mathrm{mg} \cdot \mathrm{kg}^{-1}$ succinylcholine $i v$. Anesthesia was maintained with isoflurane, $0.8-2.0 \%$ inspired, in nitrous oxide $\left(\mathrm{N}_{2} \mathrm{O}\right) 50 \%$ in oxygen $\left(\mathrm{O}_{2}\right)$ $50 \%$ and vecuronium. Isoflurane concentrations were adjusted according to response to vital signs such as systolic blood pressure and heart rate, which were controlled within $20 \%$ of preoperative values. No opioids or other analgesics were used during anesthesia. A 20 gauge arterial catheter was placed in the left radial artery to measure blood pressure and to obtain arterial blood samples. The end-expiratory (ET) concentration of oxygen, carbon dioxide $\left(\mathrm{CO}_{2}\right)$ and anesthetics were monitored throughout anesthesia using a 5250 RGM Analyzer (Ohmeda, Madison, USA). The lungs were mechanically ventilated to maintain $\mathrm{P}_{\mathrm{ET}} \mathrm{CO}_{2}$ at $35-45$ $\mathrm{mmHg}$ and $7 \mathrm{ml} \cdot \mathrm{kg}^{-1}$ lactated Ringer's solution was infused. Patients received no other fluid replacement or packed red blood cells. Naso-pharyngeal temperature was monitored continuously with an electric thermistor and maintained at $36.0-37.0^{\circ} \mathrm{C}$ using a warming blanket and the temperature in the operating room was controlled to avoid hormonal effects. Postoperatively, all patients were treated with a non-steroidal analgesic (50 mg diclofenac pr) every eight hours for incisional pain.

Blood samples, $5 \mathrm{ml}$, were obtained from the arterial cannula before and $15 \mathrm{~min}$ after induction of anesthesia, $15 \mathrm{~min}$ after skin incision, and $60 \mathrm{~min}$ after the end of surgery, into tubes containing EDTA. The first sample was taken at 8:30 a.m. The samples were immediately centrifuged and stored at $-80^{\circ} \mathrm{C}$ until analysis. Plasma EPI and NE concentrations were measured by gas chromatography and electron impact mode mass spectrometry with selected ion method (JMS-D300 GC-MS, Japan electronic CO, Tokyo, Japan). $1 \mathrm{ml}$ of plasma were acidified ( $1 \mathrm{ml} 0.2 \mathrm{M}$ Tris HCL) and extracted using alumina cartridges (Wako 
TABLE Background and hemodynamic status during anaesthesia.

\begin{tabular}{|c|c|c|c|c|}
\hline & Group 1 & Group 2 & Group $A$ & Group $B$ \\
\hline Number of patients $(\mathrm{F} / \mathrm{M})$ & $18(10 / 8)$ & $18(9 / 9)$ & $7(4 / 3)$ & $12(6 / 6)$ \\
\hline Age (yr) & $88.2 \pm 1.3 \dagger$ & $52.6 \pm 1.7$ & $71.5 \pm 1.8$ & $69.7 \pm 1.2$ \\
\hline Weight (kg) & $43.9 \pm 1.8^{*}$ & $53.5 \pm 1.8$ & $48.5 \pm 1.7$ & $51.0 \pm 1.6$ \\
\hline Body mass index (BMI) & $19.5 \pm 0.6^{*}$ & $21.2 \pm 0.9$ & $20.1 \pm 0.5$ & $20.4 \pm 0.6$ \\
\hline Duration of surgery (min) & $66.3 \pm 3.9$ & $71.3 \pm 3.6$ & $67.1 \pm 3.4$ & $62.7 \pm 3.8$ \\
\hline Duration of anaesthesia (min) & $123.4 \pm 4.6$ & $134.5 \pm 5.0$ & $126.3 \pm 5.4$ & $120.5 \pm 4.5$ \\
\hline Blood loss (ml) & $102.0 \pm 9.2$ & $94.8 \pm 9.4$ & $94.5 \pm 7.4$ & $99.5 \pm 11.7$ \\
\hline \multicolumn{5}{|l|}{ Systolic blood pressure ( $\mathrm{mmHg}$ ) } \\
\hline before induction & $151.7 \pm 2.3^{*}$ & $130.6 \pm 2.5$ & $148.3 \pm 3.5$ & $143.8 \pm 2.6$ \\
\hline $15 \mathrm{~min}$ after induction & $137.4 \pm 3.2^{\star}$ & $117.1 \pm 3.2$ & $140.2 \pm 2.9$ & $139.3 \pm 2.8$ \\
\hline $15 \mathrm{~min}$ after skin incision & $164.7 \pm 3.5^{*}$ & $138.9 \pm 3.4$ & $157.0 \pm 2.7$ & $154.6 \pm 3.4$ \\
\hline 60 min after end of surgery & $147.1 \pm 3.5^{*}$ & $135.9 \pm 3.3$ & $150.6 \pm 3.4$ & $145.0 \pm 2.7$ \\
\hline \multicolumn{5}{|l|}{ Diastolic blood pressure $(\mathrm{mmHg})$} \\
\hline before induction & $77.5 \pm 3.3$ & $74.5 \pm 3.5$ & $76.3 \pm 2.1$ & $75.1 \pm 2.3$ \\
\hline 15 min after induction & $73.1 \pm 2.8$ & $71.6 \pm 2.8$ & $73.9 \pm 2.5$ & $73.0 \pm 2.7$ \\
\hline 15 min after skin incision & $79.6 \pm 2.5$ & $76.1 \pm 3.0$ & $79.3 \pm 2.2$ & $76.9 \pm 2.5$ \\
\hline $60 \mathrm{~min}$ after end of surgery & $77.2 \pm 2.7$ & $74.3 \pm 3.5$ & $76.6 \pm 3.0$ & $74.7 \pm 3.1$ \\
\hline \multicolumn{5}{|l|}{ Heart rate $(\mathrm{bpm})$} \\
\hline before induction & $79.5 \pm 3.0$ & $74.7^{\prime} \pm 2.5$ & $79.8 \pm 2.3$ & $78.8 \pm 2.0$ \\
\hline 15 min after induction & $76.9 \pm 2.7$ & $72.0 \pm 2.3$ & $79.2 \pm 2.5$ & $75.0 \pm 3.5$ \\
\hline $15 \mathrm{~min}$ after skin incision & $80.3 \pm 2.4$ & $76.6 \pm 2.8$ & $81.4 \pm 2.9$ & $78.4 \pm 3.4$ \\
\hline $60 \mathrm{~min}$ after end of surgery & $78.1 \pm 2.8$ & $78.2 \pm 3.0$ & $77.5 \pm 3.2$ & $76.2 \pm 2.7$ \\
\hline
\end{tabular}

Mean $\pm S E M . ~ *: P<0.05, \dagger: P<0.01$ group 1 vs group 2 .

purechemical industries $\mathrm{CO}$, Tokyo, Japan). The lower limit of assay detection were $2 \mathrm{pg} \cdot \mathrm{ml}^{-1}$ for $\mathrm{E}$ and $1 \mathrm{pg} \cdot \mathrm{ml}^{-1}$ for NE. The coefficient of variation (CV) was $<8.4 \%$ for $\mathrm{E}$ and $<9.3 \%$ for NE. Plasma ACTH and cortisol were measured by radioimmunoassay using ACTH kit (CIS, Tokyo, Japan). Plasma ACTH levels were determined with the intra-assay and interassay coefficient of variation of $5.6 \%$ and $8.7 \%$, respectively. Plasma cortisol levels were determined with spectrometry using cortisol kit (Daiich Pharmaceutical Co, Tokyo, Japan) with CV of $1.5 \%$.

Patient data were analyzed with Student's unpaired $t$ test. Changes in endocrine data over time within each group were analyzed by using repeated measures ANOVA followed by Bonferroni's correction. Data were expressed as mean \pm standard error of the mean. Difference in mean values were considered significant at $P<0.05$.

\section{Results}

Mean age was $88.2 \pm 1.3 \mathrm{yr}$ for the group $1,52.6 \pm$ $1.7 \mathrm{yr}$ for the group $2,71.5 \pm 1.8 \mathrm{yr}$ for the group $\mathrm{A}$ and $69.7 \pm 2.2 \mathrm{yr}$ for the group B. Systolic BP of parients in group 1 at all measurement points was higher than those of group 2 . There were no differences in any other hemodynamic data throughout the perioperative course between group 1 and 2 . There were no differences in hemodynamic data between group $A$ and $B$ during anesthesia (Table I).

\section{Endocrine response of elderly patients to surgical stress} The increasing plasma EPI concentrations during surgery were not different between groups 1 and 2 . Plasma NE level of group 1 before the induction of anesthesia was higher than that of group 2. The increase in the plasma NE level in group 1 (274\%), 15 min after skin incision, was higher than that in group $2(191 \%)$. There was no relationship between plasma norepinephrine concentration and the increase of systolic blood pressure in groups 1 and 2. Plasma ACTH concentrations of group 1 were not observed no differences as compared with those of group 2 through perioperative course. Mean plasma cortisol concentrations $\left(40.4 \pm 4.7\right.$ and $\left.44.1 \pm 5.2 \mu \mathrm{g} \cdot \mathrm{dl}^{-1}\right)$ of group $\mathrm{l}$, $15 \mathrm{~min}$ after skin incision and $60 \mathrm{~min}$ after the end of surgery, were higher than in group $2(29.8 \pm 3.5$ and $22.3 \pm 3.0 \mu \mathrm{g} \cdot \mathrm{dl}^{-1}$ ) (Figure 1).

\section{Endocrine response of patients with Alzbeimer disease to surgical stress}

Plasma NE $\left(1092.9 \pm 112.0 \mathrm{pg} \cdot \mathrm{ml}^{-1}\right)$ and cortisol levels $\left(53.4 \pm 5.8 \mu \mathrm{g} \cdot \mathrm{dl}^{-1}\right)$ of group A were higher than in group B $\left(772.6 \pm 82.4 \mathrm{pg} \cdot \mathrm{ml}^{-1}\right.$ and $41.7 \pm 4.3$ $\mu \mathrm{g} \cdot \mathrm{dl}^{-1}$ ) $15 \mathrm{~min}$ after the skin incision. The increase of 
plasma NE (261\%), 15 min after skin incision, in group A was higher than in group B (206\%) (Figure 2). There were no differences in plasma EPI and ACTH levels between groups $A$ and $B$.

\section{Discussion}

\section{Endocrine response of elderly patients to surgical stress}

The present study showed that the increase of plasma NE during surgical stress was greater in $\mathbf{8 0 - 9 9}$ yr old patients than in those aged 40-59 yr, but the response of plasma EPI to surgical stress did not change with age. Lehmann and Keul ${ }^{2}$ reported that baseline NE concentrations were higher in the elderly and plasma EPI concentrations were similar to those of young adults. The alteration in NE with age may be caused by a compensatory mechanism which depends both on decreased baroreflex function and on decreased $B$ adrenoceptor responsiveness. ${ }^{2}$ As a result, the increases in sympathetic nerve firing rate and a decrease in

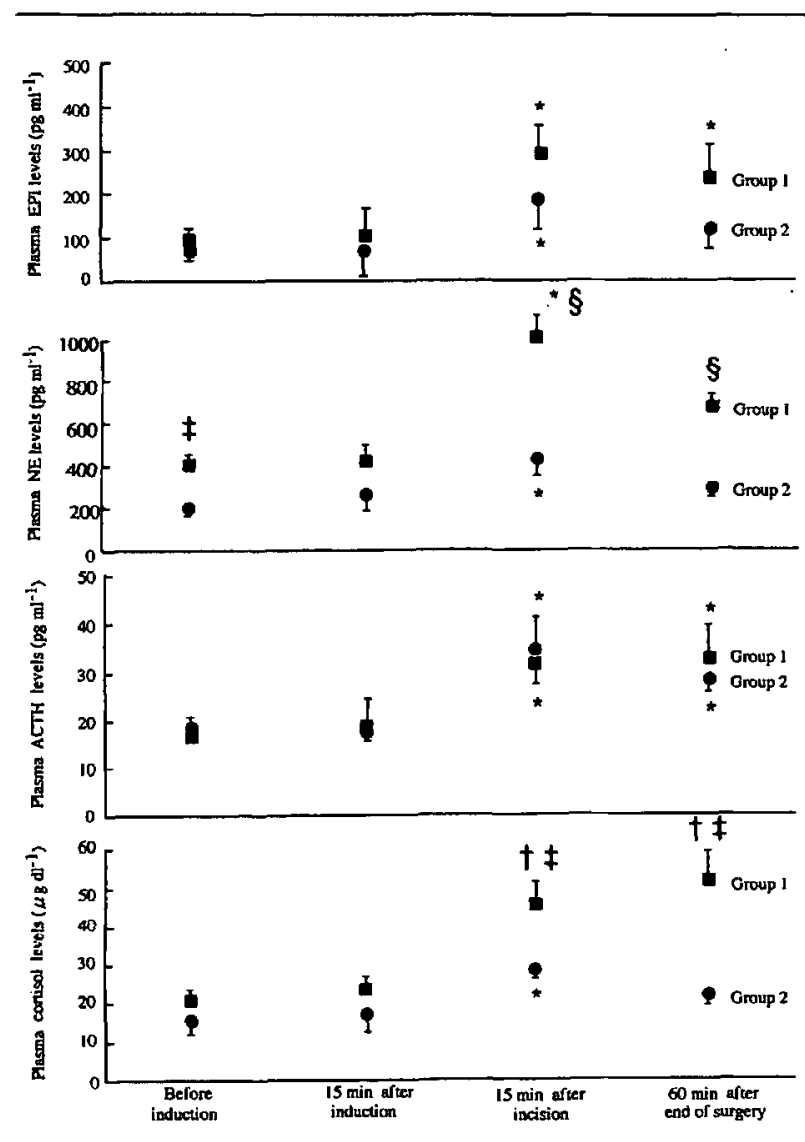

FIGURE 1 Plasma epinephrine, norepinephrine, ACTH and cortisol levels before and $15 \mathrm{~min}$ after induction, $15 \mathrm{~min}$ after skin incision, and $60 \mathrm{~min}$ after end of surgery. Mean \pm SEM.

$\star: P<0.05, \dagger: P<0.01$ vs before induction of anesthesia. $\ddagger: P<$ $0.05, \S: P<0.01$ vs group 2 . plasma NE clearance and impairment of the neuronal reuptake of the neurotransmitter by sympathetic nerve would contribute to the increase in plasma NE concentration in the elderly. ${ }^{13,14}$ The increase in plasma $\mathrm{NE}$ concentration in response to a variety of different stress including mental stress, isometric and aerobic exercise and hypoglycemia is also greater in older than in younger people. . $^{3,4}$ Thus, in this study, the increased plasma NE response to surgical stress appears to be affected by sympathetic activation with aging. On the other hand, the exercise-induced EPI response was less prominent in the elderly compared to the NE response. $^{2}$ Our results showed that no change in the response of plasma EPI to surgical stress was associated with aging. The differences between EPI and NE would be related to their clearance from the circulation, as EPI clearance is not different in the old and young. 9 Although the increase in plasma NE concentrations in group 1 were greater than that in group 2 , there was no relationship between plasma norepinephrine concentration and the increase of systolic blood pressure in group 1 compared with group 2 patients. This may be due to decreased $B$-adrenoceptor responsiveness with elderly patients.

The effects of aging on baseline HPA function remain controversial. Issa et al. ${ }^{7}$ proposed that stressors elicit greater activation of the HPA axis in aging. De Leon $e t a l^{16}$ suggested that the degree of hippocampal

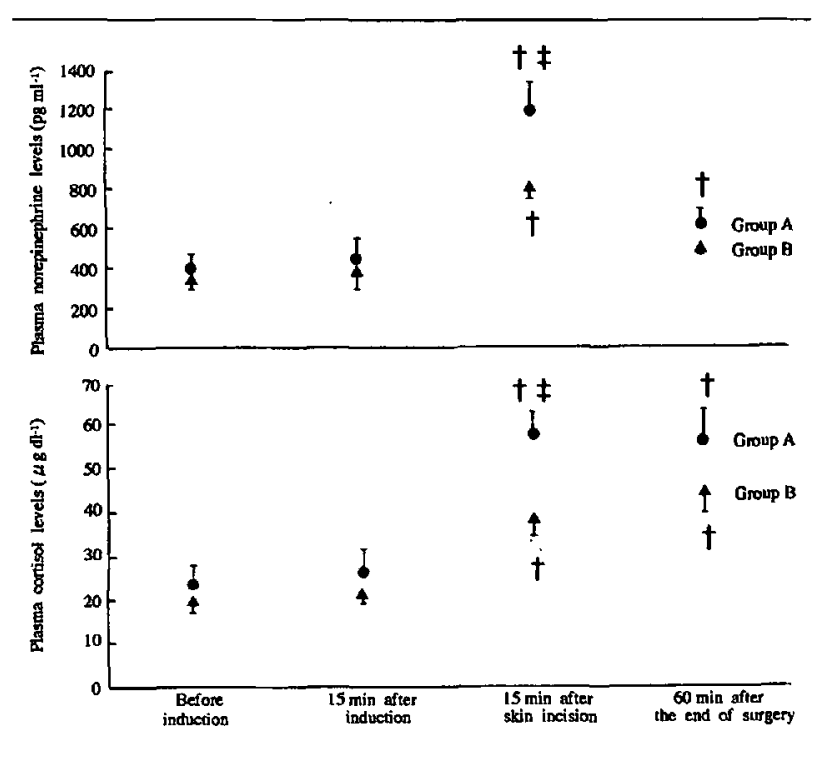

FIGURE 2 Plasma norepinephrine and cortisol levels in elderly with (group A) and withour (group B) Alzheimer's disease before and $15 \mathrm{~min}$ after induction, $15 \mathrm{~min}$ after skin incision, and $60 \mathrm{~min}$ after end of surgery. Mean \pm SEM.

${ }^{\star}: P<0.05, f: P<0.01 \quad v s$ before induction of anesthesia. $\ddagger: P<$ 0.05 vs group $B$. 
damage paralleled the magnitude of hypercortisolism, since the hippocampus is thought to exert an inhibitory control on the HPA axis. The activity of the HPA system is controlled by mineralocorticoid and glucocorticoid receptor systems in hippocampus. ${ }^{17}$ Thus, hyperactivation of the HPA with aging may be caused by decreased hippocampal inhibition due to a negative feedback regulation in response to a decreased sensitivity of the mineralocorticoid and corticosteroid receptor. On the other hand, Ait-Chaoui $e t a l .^{18}$ showed that there was marked age-related attenuation in the ACTH-induced increase in plasma cortisol of old rats. This discrepancy may have resulted from methodological differences. Our result supports that of Issa $e t$ al. ${ }^{7}$ However, no difference in the plasma ACTH response to surgical stress was observed in young and elderly patients. Sonntag et al. ${ }^{8}$ demonstrated that adrenal sensitivity to ACTH was greater in old rats than in young or middle-aged rats. Thus, the greater increase in adrenal sensitivity of old patients appears to be related to increase in cortisol release from adrenal medulla. In addition, as the cortisol secretion is increased not only by the stimulation of ACTH, but also by the activated $\mathrm{NE},{ }^{19}$ the activated NE system with aging may partly result in the elevated plasma cortisol during surgery. Therefore, the age-related increase in plasma cortisol response to surgical stress would include several factors.

\section{Endocrine response of patients with Alzheimer disease to surgical stress}

The decline in hypothalamic and hippocampal catecholamine activity has a critical role in the development of the aging process. ${ }^{5}$ In $\mathrm{AD}$, hippocampal noradrenergic activity has a potentially important implication for pathogenesis of this disorder and the elevated plasma $\mathrm{NE}$ concentrations may indicate the severity of $\mathrm{AD} .^{6}$ The present study showed that plasma NE concentration during surgery in patients with $\mathrm{AD}$ was higher than that in patients of the same ages without $\mathrm{AD}$. This confirms the report that sympathetic response to stress is functionally impaired in $\mathrm{AD} .{ }^{15}$ Thus, the age-related elevation of plasma NE may become more pronounced when patients complicated with $\mathrm{AD}$.

The elevated cortisol response to surgical stress was elevated also in patients with $\mathrm{AD}$. Hyperactivity of the adrenal cortex has been described in $\mathrm{AD} .{ }^{10}$ The cortisol levels after corticotropin-releasing factor administration are higher in patients with $\mathrm{AD}$ than in normal elderly patient. ${ }^{20}$ The hippocampus is a brain site that plays an important role in the regulation of the stress-adaptive and -responsive HPA system and is nearly always damaged in $\mathrm{AD} .{ }^{11}$ In $\mathrm{AD}$, it was shown that the degree of hippocampal damage paralleled the magnitude of hypercortisolism. ${ }^{16}$ Thus, hippocampal degeneration is likely to play an remarked role in the cortisol activation with aging and $\mathrm{AD}$.

We reported previously that isoflurane has no influence on plasma catecholamine, ACTH, and cortisol concentration and, after skin incision, these hormones are increased and continue to increase during isoflurane anesthesia. ${ }^{21}$ Thus, as isoflurane does not affect these hormones, we can estimate the effect of surgical stress on pituitary adrenal function without intervention. On the other hand, the use of opioids suppresses the endocrine response to surgical stress. In addition, the fentanyl concentration required to provide adequate analgesia varies over a wide range of $I$ $5 \mathrm{ng} \cdot \mathrm{ml}^{-1} .{ }^{22}$ The individual broad variability in the serum levels reflects diverse individual sensitivities to fentanyl. The difference of the individual sensitivities to opioids may affect the endocrine response. Thus, no opioids were used in this study. We may have underestimated the true adrenergic response in this study. Compared with venous blood, arterial blood contains lower concentrations of $\mathrm{NE}^{23}$ This may be associated with the release of NE at sympathetic nerve terminal, which is taken up as the blood passes from the arterial to the venous circulation. Thus, the true plasma NE concentration in this study may have been higher than reported.

In summary, we found an increase of plasma $\mathrm{NE}$ and cortisol response to surgical stress in orthopedic patients aged 80-99 yr. Plasma NE and cortisol responses to surgical stress were also stimulated in elderly patients with Alzheimer's disease. These findings suggest that NE and cortisol play an essential role in maintaining homeostasis in old patients during surgery.

\section{Acknowledgments}

The authors are grateful to Tsuyoshi Kudo and Mihoko Kudo for excellent technical assistance.

\section{References}

I Hoeldlke $R D$, Cilmi KM. Effects of aging on catecholamine metabolism. J Clin Endcrinol Metab 1985; 60: 479-84.

2 Lehmann M, Keul J. Age-associated changes of exercise-induced plasma catecholamine responses. Eur J Appl Physiol 1986; 55: 302-6.

3 Esler MD, Thompson JM, Kaye DM, et al. Effects of aging on the responsiveness of the human cardiac sympathetic nerves to stressors. Circulation 1995; 91: 351-8.

4 Young JB, Rowe JW, Pallotta JA, Sparrow D, Landsberg $L$. Enhanced plasma norepinephrine response to upright posture and oral glucose administration in elderly human subjects. Metabolism 1980; 29: 532-9. 
5 Meites J. Aging: hypothalamic catecholamines, neuroendocrine-immune interactions, and dietary restriction. Proc Soc Exp Biol Med 1990; 195: 304-11.

6 Raskind MA, Peskind ER, Halter JB, Jimerson DC. Norepinephrine and MHPG levels in CSF and plasma in Alzheimer disease. Arch Gen Psychiatry 1984; 41 : 343-6.

7 Issa AW, Rowe W, Gauthier S, Meaney MJ. Hypothalamic-pituitary-adrenal activity in aged, cognitively impaired and cognitively unimpaired rats. J Neurosci 1990; 10: 3247-54.

8 Sonntag WE, Golieszek AG, Brodish A, Eldridge JC. Diminished diurnal secretion of adrenocorticotropin (ACTH), but not corticosterone, in old male rats: possible relation to increased sensitivity to ACTH in vipo. Endocrinology 1987; 120: 2308-15.

9 Brett LP, Chong GS, Coyle S, Levine S. The pituitaryadrenal response to novel stimulation and ether stress in young adult and aged rats. Neurobiol Aging 1983; 4: 133-8.

10 Davis KL, Davis BM, Greenwald BS, et al. Cortisol and Alzheimer's disease, I: basal studies. Am J Psychiatry 1986; 143: 300-5.

11 Greenwald BS, Mathé AA, Mobs RC, Levy MI, Jobns $C A$, Davis KL. Cortisol and Alzheimer's disease, II: dexamethasone suppression, dementia severity, and affective symptoms. Am J Psychiatry 1986; 143: 442-6.

12 Sapolsky RM, Plotsky PM. Hypercortisolism and its possible neural bases. Biol Psychiatry 1990; 27: 937-52.

13 Morrow LA, Linares $O A$, Hill TJ, et al. Age differences in the plasma clearance mechanisms for epinephrine and norepinephrine in humans. J Clin Endocrinol Metab 1987; 65: 508-11.

14 Esler MD, Turner AG, Kaye DM, et al. Aging effects of aging on human sympathetic neuronal function. Am J Physiol 1995; 268: R278-85.

15 Vitiello $B$, Veith $R C$, Molchan SE, et al. Autonomic dysfunction in parients with dementia of the Alzheimer's type. Biol Psychiatry 1993; 34: 428-33.

16 De Leon MJ, McRae T, Tsai JR, et al. Abnormal cortisol response in Alzheimer's disease linked to hippocampal atrophy. Lancet 1988; 13: 391-2.

17 De Kloet ER. Brain corticosteroid receptor balance and homeostatic control. Front Neuroendocrinol 1991; 12: 95-164.

18 Ait Chaouri A, Rakotondrazafy J, Brudieux R. Agerelated changes in plasma corticosterone and aldosterone responses to endogenous ACTH in the rat. Horm Res 1995; 43: 181-7.

19 Udelsman R, Holbrook NJ. Endocrine and molecular responses to surgical stress. In: Wells SA Jr (Ed.). Current Problems in Surgery 1994; 31: 655-720.
20 Martigononi E, Petraglia $F$, Costa $A$, et al. Dementia of the Alzheimer type and hypothalamus-pituitaryadrenocortical axis: changes in cerebrospinal fluid corticotropin releasing factor and plasma cortisol levels. Acta Neurol Scand 1990; 81: 452-6.

21 Iida $T$, Tsubo T, Hirota $K$, Kudou M, Matsuki $A$, Oyama $T$. Effects of isoflurane anesthesia and surgery on endocrine function in man. (Japanese) Masui 1987; 36: 568-75.

22 White PF, Dworsky WA, Horai $\Upsilon$, Trevor AJ. Comparison of continuous infusion fentanyl or ketamine versus thiopental-determining the mean effective serum concentrations for outpatient surgery. Anesthesiology 1983; 59: 564-9.

23 Esler $M$, Jennings G, Korner P, Blombery P, Sacharias N, Leonard $P$. Measurement of total and organ-specific norepinephrine kinetics in humans. Am J Physiol 1984; 247: E21-8. 